\title{
Author Correction: Electrochemical Sensor for Detection of miRs Based on the Differential Effect of Competitive Structures in The p19 Function
}

\author{
E. Ghazizadeh", R. K. Oskuee ${ }^{1}$, M. R. Jaafari' ${ }^{2,3}$ \& S. Hosseinkhani ${ }^{4}$ \\ Correction to: Scientific Reports https://doi.org/10.1038/s41598-018-22098-y, published online 28 February 2018
}

The original version of this Article contained an error in Affiliation 2 which was incorrectly given as 'Biotechnology Research Center, Nanotechnology Research Center, School of Pharmacy, Mashhad University of Medical Sciences, Mashhad, Iran'. The correct affiliation is listed below:

Biotechnology Research Center, Pharmaceutical Technology Institute, Mashhad University of Medical Sciences, Mashhad, Iran.

In addition, the original version of this Article omitted an affiliation for M. R. Jaafari. The correct affiliations are listed below:

Biotechnology Research Center, Pharmaceutical Technology Institute, Mashhad University of Medical Sciences, Mashhad, Iran.

Department of Pharmaceutical Nanotechnology, School of Pharmacy, Mashhad University of Medical Sciences, Mashhad, Iran.

These errors have now been corrected in the HTML and PDF versions of this Article, and in the accompanying Supplementary Information file.

(i) Open Access This article is licensed under a Creative Commons Attribution 4.0 International License, which permits use, sharing, adaptation, distribution and reproduction in any medium or format, as long as you give appropriate credit to the original author(s) and the source, provide a link to the Creative Commons license, and indicate if changes were made. The images or other third party material in this article are included in the article's Creative Commons license, unless indicated otherwise in a credit line to the material. If material is not included in the article's Creative Commons license and your intended use is not permitted by statutory regulation or exceeds the permitted use, you will need to obtain permission directly from the copyright holder. To view a copy of this license, visit http://creativecommons.org/licenses/by/4.0/.

(C) The Author(s) 2018

${ }^{1}$ Department of Medical Biotechnology, School of Medicine, Mashhad University of Medical Sciences, Mashhad, Iran. ${ }^{2}$ Biotechnology Research Center, Pharmaceutical Technology Institute, Mashhad University of Medical Sciences, Mashhad, Iran. ${ }^{3}$ Department of Pharmaceutical Nanotechnology, School of Pharmacy, Mashhad University of Medical Sciences, Mashhad, Iran. ${ }^{4}$ Department of Biochemistry, Faculty of Biological Sciences, Tarbiat Modares University, Tehran, Iran. Correspondence and requests for materials should be addressed to M.R.J. (email: JafariMR@ mums.ac.ir) 